\title{
Real-world treatment and survival of patients with advanced non-small cell lung Cancer: a German retrospective data analysis
}

Fränce Hardtstock ${ }^{1 *}$, David Myers ${ }^{2}$, Tracy Li ${ }^{3}$, Diana Cizova ${ }^{1}$, Ulf Maywald ${ }^{4}$, Thomas Wilke ${ }^{1}$ and Frank Griesinger ${ }^{5}$

\begin{abstract}
Background: The objective of this study was to describe the real-world treatment and overall survival (OS) of German patients with a diagnosis of advanced non-small cell lung cancer (aNSCLC), and to explore factors associated with the real-world mortality risk.
\end{abstract}

Methods: This was a retrospective German claims data analysis of incident aNSCLC patients. Data were available from 01/01/2011 until 31/12/2016. Identification of eligible patients took place between 01/01/2012-31/12/2015, to allow for at least 1-year pre-index and follow-up periods. Inpatient and outpatient mutation test procedures after aNSCLC diagnosis were observed. Further, prescribed treatments and OS since first (incident) aNSCLC diagnosis and start of respective treatment lines were described both for all patients and presumed EGFR/ALK/ROS-1-positive patients. Factors associated with OS were analyzed in multivariable Cox regression analysis.

Results: Overall, 1741 aNSCLC patients were observed (mean age: 66.97 years, female: 29.87\%). The mutation test rate within this population was $26.31 \%(n=458), 26.6 \%$ of these patients $(n=122)$ received a targeted treatment and were assumed to have a positive EGFR/ALK/ROS-1 test result. Most often prescribed treatments were pemetrexed monotherapy as $1 \mathrm{~L}(21.23 \%$ for all and $11.11 \%$ for mutation-positive patients) and erlotinib monotherapy as $2 \mathrm{~L}$ (25.83\%/38.54\%). Median OS since incident diagnosis was 351 days in all and 571 days in mutation-positive patients. In a multivariable Cox regression analysis, higher age, a stage IV disease, a higher number of chronic drugs in the pre-index period and no systemic therapy increased the risk of early death since first aNSCLC diagnosis. On the other hand, female gender and treatment with therapies other than chemotherapy were associated with a lower risk of early death.

Conclusions: Despite the introduction of new treatments, the real-world survival prognosis for aNSCLC patients remains poor if measured based on an unselected real-world population of patients. Still, the majority of German aNSCLC patients do not receive a mutation test.

Keywords: Non-small cell lung cancer, Advanced NSCLC, Mutation testing, Overall survival

\footnotetext{
* Correspondence: fraence.hardtstock@ipam-wismar.de

${ }^{1}$ IPAM e.V, Alter Holzhafen 19, 23966 Wismar, Germany

Full list of author information is available at the end of the article
}

(c) The Author(s). 2020 Open Access This article is licensed under a Creative Commons Attribution 4.0 International License, which permits use, sharing, adaptation, distribution and reproduction in any medium or format, as long as you give appropriate credit to the original author(s) and the source, provide a link to the Creative Commons licence, and indicate if changes were made. The images or other third party material in this article are included in the article's Creative Commons licence, unless indicated otherwise in a credit line to the material. If material is not included in the article's Creative Commons licence and your intended use is not permitted by statutory regulation or exceeds the permitted use, you will need to obtain permission directly from the copyright holder. To view a copy of this licence, visit http://creativecommons.org/licenses/by/4.0/. The Creative Commons Public Domain Dedication waiver (http://creativecommons.org/publicdomain/zero/1.0/) applies to the data made available in this article, unless otherwise stated in a credit line to the data. 


\section{Background}

Lung cancer is the leading cause of cancer death in men and the third most frequent cause of cancer death in women worldwide, with 2.1 million new cases and 1.7 million deaths estimated for 2018 [1, 2]. In women, according to latest mortality projections, lung cancer agestandardized mortality rate will surpass breast cancer mortality rate before 2030 in many countries [3]. Nonsmall cell lung cancer (NSCLC) accounts for approximately $85 \%$ of all diagnosed lung cancer cases [4]. The 5 -year overall survival (OS) of advanced NSCLC (aNSCLC) is about $26 \%$ in stage IIIB and $10 \% / 1 \%$ in stage IVA/IVB patients [5].

The discovery of new molecular alterations and development of respective targeted treatments represents a major improvement over conventional chemotherapy when applied to appropriately selected patient populations [6-11]. A recent network meta-analysis on the tyrosine kinase inhibitors (TKIs) gefitinib, erlotinib and afatinib concluded in this respect that these three agents out-performed chemotherapy in terms of progression free survival (PFS), overall response rate, and disease control rate, with less clearer results with regard to OS. Similar results were shown in another meta-analysis on erlotinib only [12]. In contrast, a recent German observational study on EGFR-positive aNSCLC patients concluded that those patients who ever received a TKI during their complete therapy course, compared with those who never received a TKI, had a higher OS (median 18.4 versus 13.6 months; HR $0.53 ; p=0.003$ ) [13, 14].

In addition to targeted agents, recent development of immune checkpoint inhibitors such as pembrolizumab or nivolumab adds extends treatment options for aNSCLC patients, with reported median OS in clinical trials of $9.2-12.2$ months (Nivolumab) and 10.4-12.7 months (Pembrolizumab, PD-L1+ patients) versus 6.09.4 months (Docetaxel) for chemotherapy [15-17]. On the other hand, in patients not suitable for targeted and/ or immunotherapies conventional chemotherapy was still the treatment of choice until January of 2016, when pembrolizumab 1st line was approved for patients with a PD-L1 expression of $>50 \%$ [18]. OS prognosis for these patients remains poor [19-21].

Based on recent therapy developments, current European and German treatment guidelines recommend testing for mutations/mutation aberrations (EGFR, ALK, ROS-1, MET, NTRK) and PD-L1 testing, in order to identify those patients who are eligible for targeted/immune checkpoint therapies [18, 22, 23]. However, as testing procedures are associated with additional health care resource use and cost, and many questions around proper patient selection, optimal sequential/combinatorial use of agents, appropriate treatment duration etc. are still unanswered, there is an ongoing discussion about whether recent therapy developments were also associated with superior outcomes in the real-world treatment of aNSCLC patients. As most real-world data have been collected in retrospective medical chart reviews or prospective observational studies, results reported so far might be biased because of study site/patient selection procedures in these study types. That is why, the main aim of this study was to report data on mutation testing rates and treatment patterns as well as OS of aNSCLC patients in the real world, based on an unselected patient population identified in a large German claims dataset.

\section{Methods}

\section{Data source}

This was a retrospective claims-based data analysis of patients diagnosed with aNSCLC, using a cohort design. The study utilized data provided by the statutory German sickness fund AOK PLUS, covering routine data on health of 3.2 million people insured in Germany (regions of Saxony/Thuringia), which is more than $50 \%$ of the overall population in these states. This large claims data set includes complete records of a patient's outpatient and inpatient diagnoses and treatments prescribed by all types of treating physicians and departments within the German healthcare system. Diagnoses were identified based on inpatient and confirmed outpatient ICD-10 codes (international classification of diseases 10th revision). Outpatient drug treatment was identified through relevant ATC-codes, and inpatient treatment was identified through relevant operational and procedure codes (OPS). The dataset covered the period 01/01/2011-31/ $12 / 2016$.

\section{Patient selection}

Identification and inclusion of eligible patients took place between $01 / 01 / 2012-31 / 12 / 2015$, with a baseline period of one year and a minimum follow-up period of 1 year. Patients were selected in a stepwise procedure based on their diagnoses and treatments (Fig. 1). In the first step, all patients with at least one inpatient and/or outpatient diagnosis of lung cancer (ICD-10: C34) between 01/01/2012-31/12/2015 were identified. Second, only patients continuously insured with the respective sickness fund (death being the only exception) between 01/01/2011-31/12/2016 were further analyzed. Third, as no ICD-10 code specifies type of lung cancer, NSCLC patients were identified based on documented NSCLCspecific treatments prescribed after their lung cancer diagnosis. Treatment was defined as NSCLC-specific by consulting the latest treatment guideline in Germany [24] and the official Summary of Product Characteristics (SmPCs) of the respective drugs [25]. Patients with any treatment approved for SCLC, or with a treatment 


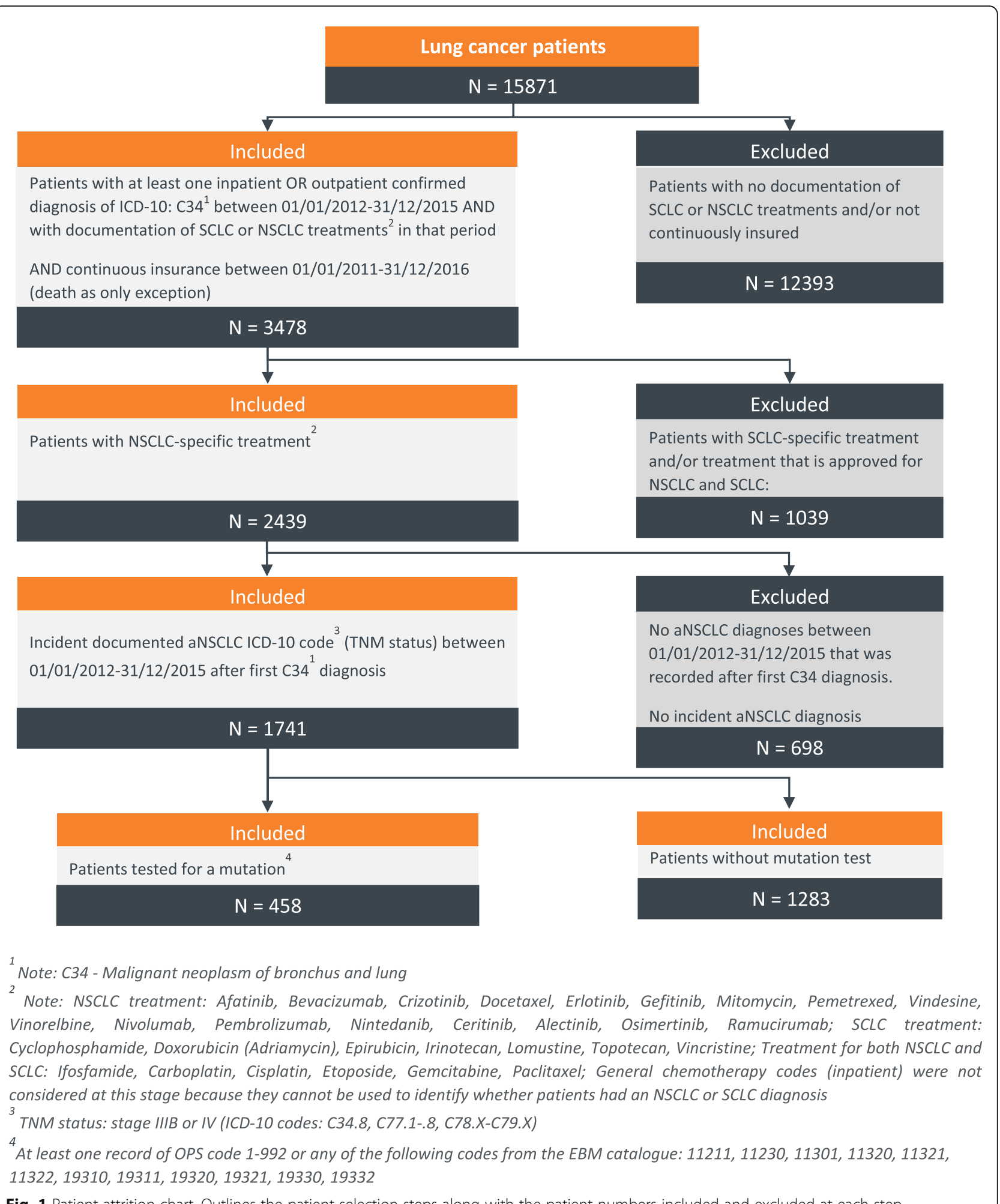

Fig. 1 Patient attrition chart. Outlines the patient selection steps along with the patient numbers included and excluded at each step

approved for both SCLC and NSCLC were excluded. The complete list of SCLC and NSCLC-specific drugs (Supplementary Table 1) was additionally reviewed by an oncologist.
Fourth, out of all patients with NSCLC, patients with advanced disease stage were identified based on their tumor stage at the time of their lung cancer diagnosis. Tumor staging was evaluated with respect to the German 
treatment guidelines and the 8th edition of the Union for International Cancer Control's (UICC) tumor classification, with status IIIb or higher classifying a patient as being advanced within this study. Patients with at least one confirmed inpatient or outpatient diagnosis of tumor stage IIIb or higher between 01/01/2012-31/12/2015, following/concurrent with their first observed general lung cancer diagnosis, were included (Supplementary Table 2). Fifth, only patients who did not already receive a diagnosis of advanced tumor stage in the 12 months baseline period before index date (first aNSCLC diagnosis in inclusion period) were classified as being incident aNSCLC patients.

All patients were observed for at least 12 months following their index date (or until death, whatever came first). In case of data availability, for a subset of patients, 24-month and 36-month follow-up data were analyzed.

\section{Identification of mutation testing and respective results}

In this study, we aimed to identify the percentage of patients with a test for an EGFR, ALK or ROS-1 mutation. Within Germany, mutation testing can be carried out in both an outpatient and an inpatient setting. Outpatient mutation tests were identified based on reimbursement codes listed in a German-wide code catalogue (Einheitlicher Bewertungsmaßstab EBM) published by the National Association of Statutory Health Insurance Physicians (Kassenärztliche Bundesvereinigung) [26]. As no unique code for above mutation tests existed in the analyzed years, we applied an extensive list of codes which were seen as proxies for a mutation test (Supplementary Table 3). Inpatient mutation tests were observed based on the documentation of a respective inpatient procedure code (OPS-code) (Supplementary Table 3). As results of the mutation tests were not available in the database, mutation-positive patients were identified under the assumption that such a mutation existed if a patient received a mutation test and, additionally, received a targeted treatment (gefitinib, erlotinib, afatinib, crizotinib) after that test (any time).

\section{Identification of treatment lines}

Treatments and treatment patterns were observed for all incident aNSCLC patients, and for the subgroup of mutation-positive aNSCLC patients as defined above. Prescribed treatments were identified based on respective anatomical therapeutic chemical classification (ATC) codes of agents, both in an inpatient and an outpatient setting. Generally, all prescribed outpatient treatments were available in our database, that also applied for inpatient treatments reimbursed separately outside the DRG (diagnosis related groups) system. For mostly older treatments that are not separately reimbursed in an inpatient setting, we used a "general" chemotherapy code (OPS 8-54) which documented a chemotherapy treatment but did not provide the specific agent. The first prescription of an agent after the incident aNSCLC diagnosis was defined as start of the first treatment line (1 L). Any agents prescribed on the same day or within 21 days of starting a treatment line were considered as part of a combination therapy. A start of a new treatment line was identified only when a new agent different from $1 \mathrm{~L}$ treatment(s) was observed after that 21 days period. Discontinuation of a treatment/treatment line was assumed if a new treatment line started or if there was a gap in drug availability of at least 45 days. In case a gap in drug availability was observed, the end of the respective gap was considered to be the end of the treatment line. In addition to that, for aNSCLC stage IIIb patients, we also reported the percentage of patients who received a radiotherapy (RT), as in these cases not necessarily a mutation test is recommended.

Identification of most frequently prescribed treatment patterns was done by observing the number of patients with a prescription of the respective monotherapy or combination therapy, within each line of therapy. Identification of the most often prescribed agents was based on all patients who received the respective agents, regardless of whether they were used as monotherapy or a combination therapy.

\section{Assessment of overall survival}

OS was described using Kaplan Meier methodology. The proportion of patients alive after 3/6/12 months following their index date (incident aNSCLC diagnosis), and in a subgroup analysis of patients with longer data availability, after 24 and 36 months, was reported. Furthermore, survival analysis was repeated, considering the start of $1 \mathrm{~L} / 2 \mathrm{~L} / 3 \mathrm{~L}$ treatment as index date.

Mean and median OS in days was estimated based on above assumptions. Moreover, an OS comparison between patients who (1) did not receive any systemic treatment after incident aNSCLC diagnosis, (2) received a mutation test and received a targeted therapy (at any line), (3) received a targeted therapy but never received a mutation test, (4) received an immunotherapy ${ }^{1}$, or (5) received chemotherapy only was done, using Log Rank tests in comparison to patient group 5 (chemotherapy only).

A multivariable Cox regression was additionally performed in order to identify the association of various independent variables such as disease stage and sociodemographic characteristics at baseline with mortality. Furthermore, type of therapy as defined above and year of incident aNSCLC diagnosis were included as independent variables.

\section{Statistical analysis}

Most reported data were based on descriptive statistical analyses. Baseline characteristics were compared between not-tested and mutation negative aNSCLC patients and 
mutation positive patients, using parametric and nonparametric tests (t-test, $\mathrm{Chi}^{2}$, Mann-Whitney-U). A multivariable logistic regression model was used to evaluate any potential explanatory variable for receiving a mutation test. Treatment, duration of treatment and OS were reported using descriptive statistics and applying a Kaplan Meier methodology (using Log rank tests whenever applicable). Finally, multivariable analysis of factors associated with mortality was done using Cox regression analysis, applying a backward elimination method to systematically exclude variables which were deemed insignificant based on a $p$-value of 0.1 or higher. Software used for data analysis and modeling included Microsoft Office Excel 2016 and Stata version 14.1 software (StataCorp. 2015. Stata Statistical Software: Release 14. College Station, TX: StataCorp LP).

\section{Results}

\section{Baseline characteristics}

Based on 15,871 identified lung cancer patients in the pre-defined inclusion period, we finally included 1741 incident aNSCLC patients, with a mean age of 67.0 years and a higher proportion of male (70.1\%) than female patients (29.9\%). At date of incident aNSCLC diagnosis, $32.2 \%$ of all observed patients received a diagnosis of stage IIIB NSCLC, $42.7 \%$ of stage IV and for $24.1 \%$ of patients both TNM stages had been documented at index date or within 30 days after index date. The mean Charlson Comorbidity Index (CCI) in the sample was 9.91. Within the 12-month pre-index period, patients received an average of 4.7 chronic drug prescriptions, and $76.0 \%$ experienced at least one hospitalization (Table 1).

Table 1 Baseline Characteristics of Study Population

\begin{tabular}{|c|c|c|c|c|c|c|c|}
\hline Variable & $\begin{array}{l}\text { All aNSCLC } \\
\text { patients }\end{array}$ & $\begin{array}{l}\text { aNSCLC patients } \\
\text { who received a } \\
\text { mutation test }\end{array}$ & $\begin{array}{l}\text { aNSCLC patients } \\
\text { who did not receive } \\
\text { a mutation test }\end{array}$ & $p$-values & $\begin{array}{l}\text { Mutation-positive } \\
\text { aNSCLC patients }\end{array}$ & $\begin{array}{l}\text { aNSCLC patients } \\
\text { without a test or with } \\
\text { negative test result }\end{array}$ & $p$-values \\
\hline N & 1741 & 458 & 1283 & $\begin{array}{l}458 \text { vs. } 1283 \\
\text { patients }\end{array}$ & 122 & 1619 & $\begin{array}{l}122 \text { vs. } 1619 \\
\text { patients }\end{array}$ \\
\hline \multicolumn{8}{|c|}{ Age at index date } \\
\hline Mean & 6697 & 6651 & $67 \cdot 13$ & 0.441 & 6617 & 67.03 & 0.633 \\
\hline $\begin{array}{l}\text { (Median | } \\
\text { SD) }\end{array}$ & (68 |10.20) & $(68 \mid 10.41)$ & $(68 \mid 10.13)$ & & $(69 \mid 11.35)$ & $(68 \mid 10.11)$ & \\
\hline \multicolumn{8}{|l|}{ Gender } \\
\hline $\begin{array}{l}\text { Female, N } \\
(\%)\end{array}$ & $520(29.87)$ & $176(38.43)$ & $344(26 \cdot 81)$ & $<0.001$ & $56(45.90)$ & $464(28.66)$ & $<0.001$ \\
\hline \multicolumn{8}{|c|}{ TNM status at index date ${ }^{1}$} \\
\hline$\| \mathrm{B}^{2}(\%)$ & $32 \cdot 17$ & $31 \cdot 00$ & $32 \cdot 58$ & 0.535 & $26 \cdot 23$ & $32 \cdot 61$ & 0.146 \\
\hline $\mathrm{IV}^{2}(\%)$ & 4371 & 4345 & 4380 & 0.896 & $41 \cdot 80$ & 43.85 & 0.660 \\
\hline $\begin{array}{l}\text { IIIB and } \\
I^{2}(\%)\end{array}$ & $24 \cdot 12$ & $25 \cdot 55$ & $23 \cdot 62$ & 0.407 & 31.97 & $23 \cdot 53$ & 0.036 \\
\hline \multicolumn{8}{|c|}{ At least 1 all-cause hospitalization in baseline ${ }^{2}$} \\
\hline $\begin{array}{l}\% \text { of } \\
\text { patients }\end{array}$ & 75.99 & $71 \cdot 18$ & $77 \cdot 71$ & 0.005 & $67 \cdot 21$ & $76 \cdot 65$ & 0.019 \\
\hline \multicolumn{8}{|c|}{ Number of chronic drugs ${ }^{2,3}$} \\
\hline Mean & $4 \cdot 70$ & 4.43 & 4.69 & 0.767 & 4.87 & 4.68 & 0.886 \\
\hline $\begin{array}{l}\text { (Median | } \\
\text { SD) }\end{array}$ & $(4 \mid 3.91)$ & $(4 \mid 4 \cdot 89)$ & $(4 \mid 3.92)$ & & $(4 \mid 4 \cdot 29)$ & (4 |3.88) & \\
\hline \multicolumn{8}{|c|}{ Charlson Comorbidity Index (CCI) ${ }^{2}$} \\
\hline Mean & 9.91 & 9.71 & 9.98 & 0.078 & 9.66 & 9.93 & 0.053 \\
\hline $\begin{array}{l}\text { (Median | } \\
\text { SD) }\end{array}$ & $(10 \mid 2 \cdot 75)$ & $(9 \mid 2 \cdot 90)$ & $(10 \mid 2)$ & & $(9 \mid 2 \cdot 62)$ & $(10 \mid 2 \cdot 76)$ & \\
\hline
\end{tabular}

Legend: Table 1 describes baseline characteristics of observed incident aNSCLC patients as well as those of subgroups based on mutation testing and results of the mutation testing

${ }^{1}$ TNM stage IIIB ICD-10 codes: C34.8, C.77.0/.1/.2/.3/.4/.5/.8; TNM stage IV ICD-10 codes: C78.X-C79.X; IIIB and IV: Patients who received which had both diagnoses on the same day or within 30 days

${ }^{2}$ Based on 12 months baseline period

${ }^{3}$ Defined as at least 2 different prescriptions per ATC class in baseline period 


\section{Mutation testing rates}

Out of 1741 observed aNSCLC patients, 458 patients (26.3\%) received a mutation test at any time between first lung cancer diagnosis and end of observational time. Out of these tested patients, 122 patients (26.6\%) received a targeted treatment and were thus assumed to be positively tested for EGFR, ALK or ROS-1 mutations. In total, this resulted in a rate of $7.0 \%$ mutation-positive patients, out of all identified incident aNSCLC patients (19.3\% of patients with a presumed negative test result, and $73.7 \%$ of patients without testing).

Among all incident aNSCLC patients, $14.41 \%$ received a RT within the first 3 months after diagnosis $(26.58 \%$ within 12 months). Among patients in stage IIIB at time of incident diagnosis $(N=560)$, corresponding numbers were $16.61 \%$ within 3 months and $29.46 \%$ within 12 months. $74.64 \%$ of aNSCLC patients within stage IIIB did not receive a mutation test. Out of those, $16.27 \%$ received a radiation therapy within 3 months (28.95\% within 12 months).

Within a multivariable logistic regression model, female gender was associated with a higher probability to receive a mutation test $(\mathrm{OR}=1.68 ; p<0.001)$, whereas at least one hospitalization in the baseline period decreased that probability (OR $0.73, p=0.012$ ). TNM status, age, $\mathrm{CCI}$ and number of previously prescribed chronic drugs were not associated with the probability to receive a mutation test (Supplementary Table 4).

\section{Treatment and treatment lines}

Based on a 12 month follow up, 5.3\% of all observed 1741 aNSCLC patients received no systemic treatment after their incident aNSCLC diagnosis, $68.8 \%$ received a $1 \mathrm{~L}$ treatment only $(1 \mathrm{~L}), 19.5 \%$ received $1 \mathrm{~L}$ and $2 \mathrm{~L}$ treatment $(1 \mathrm{~L}+2 \mathrm{~L}), 5 \cdot 2 \%$ received three lines of treatment $(1 \mathrm{~L}+2 \mathrm{~L}+3 \mathrm{~L})$, and $1.2 \%$ received more than three lines of treatment $(>3 \mathrm{~L}$; Table 2$)$. In the 122 patients who were considered to be mutation-positive, respective numbers were $6.6 \%$ (no systemic treatment), $37.7 \%(1 \mathrm{~L})$, 38.5\% (1 L + $2 \mathrm{~L}), 13.9 \%(1 \mathrm{~L}+2 \mathrm{~L}+3 \mathrm{~L})$, and $3.3 \%(>3$ $\mathrm{L})$. The mean duration of $1 \mathrm{~L} / 2 \mathrm{~L} / 3 \mathrm{~L}$ treatment was 181.7/170.8/149.6 days in all aNSCLC patients, respectively. In the mutation-positive patient sample the respective numbers were 221.7/197.0/148.6 days.

Most frequently prescribed agent (regardless of monotherapy or combination regime) as $1 \mathrm{~L}$ treatment was pemetrexed, which was prescribed in $49.0 \%$ of aNSCLC patients and $40.2 \%$ of mutation positive aNSCLC patients. The most commonly prescribed agent in $2 \mathrm{~L} / 3 \mathrm{~L}$ treatment was erlotinib $(26 \cdot 6 \% / 40 \cdot 6 \%$ as $2 \mathrm{~L}$ for all aNSCLC patients/mutation-positive patients, $20 \cdot 2 \% / 34.5 \%$ as $3 \mathrm{~L}$ ).

Table 2 Distribution of patients with regard to systemic treatment lines

\begin{tabular}{|c|c|c|c|}
\hline Variable & & aNSCLC patients & Mutation positive aNSCLC patients \\
\hline Based on a 12-month follow-up: & $N^{1}$ & 1741 & 122 \\
\hline No systemic treatment & $\%$ of patients & $5 \cdot 34 \%$ & $6 \cdot 56 \%$ \\
\hline $1 \mathrm{~L}$ treatment only & $\%$ of patients & $68.81 \%$ & $37 \cdot 70 \%$ \\
\hline $1 \mathrm{~L}+2 \mathrm{~L}$ treatment & $\%$ of patients & $19 \cdot 47 \%$ & $38.52 \%$ \\
\hline $1 \mathrm{~L}+2 \mathrm{~L}+3 \mathrm{~L}$ treatment & $\%$ of patients & $5 \cdot 17 \%$ & $13.93 \%$ \\
\hline $1 L+2 L+3 L+$ further line of treatment & $\%$ of patients & $1 \cdot 21 \%$ & $3 \cdot 28 \%$ \\
\hline Based on a 24-month follow-up: & $N^{1}$ & 1433 & 106 \\
\hline No systemic treatment & $\%$ of patients & $4.54 \%$ & $3.77 \%$ \\
\hline $1 \mathrm{~L}$ treatment only & $\%$ of patients & $60 \cdot 29 \%$ & $16 \cdot 98 \%$ \\
\hline $1 \mathrm{~L}+2 \mathrm{~L}$ treatment & $\%$ of patients & $22 \cdot 40 \%$ & $36 \cdot 79 \%$ \\
\hline $1 \mathrm{~L}+2 \mathrm{~L}+3 \mathrm{~L}$ treatment & $\%$ of patients & $8 \cdot 79 \%$ & $24.53 \%$ \\
\hline $1 L+2 L+3 L+$ further line of treatment & $\%$ of patients & $3.98 \%$ & $17.92 \%$ \\
\hline Based on a 36-month follow-up: & $N^{1}$ & 1009 & 75 \\
\hline No systemic treatment & $\%$ of patients & $3.87 \%$ & $4.00 \%$ \\
\hline $1 \mathrm{~L}$ treatment only & $\%$ of patients & $58.97 \%$ & $16.00 \%$ \\
\hline $1 \mathrm{~L}+2 \mathrm{~L}$ treatment & $\%$ of patients & $22 \cdot 30 \%$ & $29.33 \%$ \\
\hline $1 \mathrm{~L}+2 \mathrm{~L}+3 \mathrm{~L}$ treatment & $\%$ of patients & $9.71 \%$ & $20.00 \%$ \\
\hline $1 L+2 L+3 L+$ further line of treatment & $\%$ of patients & $5 \cdot 15 \%$ & $30.67 \%$ \\
\hline
\end{tabular}

Legend: Table 2 outlines the distribution of patients within the incident aNSCLC and mutation positive cohort with regard to treatment lines over various observational periods

${ }^{1}$ Note: \% of patients is based on all patients, who were observable for 12/24/36 months after their incident aNSCLC diagnosis (with the only exception being death) 
Most frequently prescribed treatment patterns as $1 \mathrm{~L}$ treatment were pemetrexed monotherapy $(21.2 \%)$, pemetrexed in combination with an unspecified agent (unknown agent documented during hospitalization) (7.7\%), and pemetrexed and bevacizumab combination therapy (7.4\%). In mutation positive patients the most commonly prescribed treatment patterns as $1 \mathrm{~L}$ were erlotinib (20.5\%), pemetrexed (11.1\%) and pemetrexed and cisplatin combination (6.8\%). Most frequently prescribed treatment patterns as $2 \mathrm{~L}$ were erlotinib (25.8\%), docetaxel $(11.3 \%)$ and pemetrexed $(8.0 \%)$ in all aNSCLC patients, and erlotinib (38.5\%), pemetrexed (7.3\%) and gefitinib (7.3\%) in the subgroup of mutation positive patients (Table 3 ).

Across all treatment lines, 70.3\% of patients received a chemotherapy only. A TKI-based therapy at any line was prescribed in $21.2 \%$ of the patients (might include chemotherapy and/or immunotherapy at other lines), an immunotherapy without a TKI was prescribed in $4.5 \%$ of patients (might include chemotherapy at other lines).
Based on 1672 patients who started a $1 \mathrm{~L}$ treatment, $187(11.2 \%)$ received at least one mutation test between incident aNSCLC diagnosis and start of $1 \mathrm{~L}$ treatment, and $197(11.8 \%)$ received at least one test afterwards (Fig. 2). Among the 187 patients tested early, 25 (1.5\% of all patients) received a targeted treatment. Among the 1485 patients not tested before $1 \mathrm{~L}$ therapy, 86 (5.1\% of all patients) received a $1 \mathrm{~L}$ treatment with a TKI. Respective numbers for $2 \mathrm{~L}$ therapy are presented in Fig. 2.

Within a multivariable logistic regression model, higher age $(\mathrm{OR}=1.01, p=0.046)$ and a higher number of prescribed chronic drugs in the 12 months baseline period $(\mathrm{OR}=1.03, p=0.055)$ increased the probability to receive a chemotherapy as $1 \mathrm{~L}$ treatment, whereas female gender $(\mathrm{OR}=0.51, p<0.001)$ and stage IV disease at index date $(\mathrm{OR}=0.60, p<0.001)$ were found to be associated with a lower probability to receive it (Supplementary Table 5).

Table 3 Most frequently prescribed treatment patterns

\begin{tabular}{|c|c|c|c|c|c|}
\hline \multirow{2}{*}{$\frac{\text { Variable }}{\mathrm{N}}$} & & \multicolumn{2}{|c|}{ aNSCLC patients } & \multicolumn{2}{|c|}{ Mutation positive aNSCLC patients } \\
\hline & & 1741 & & 122 & \\
\hline \multirow[t]{6}{*}{ As $1 \mathrm{~L}$ treatment } & Patients who started a $1 \mathrm{~L}$ treatment; $\mathrm{N}$ & 1672 & & 117 & \\
\hline & $\%$ patients with at least 1 prescription & $21 \cdot 23 \%$ & Pemetrexed & $20.51 \%$ & Erlotinib \\
\hline & & $7 \cdot 72 \%$ & Pemetrexed +Unspecified & $11 \cdot 11 \%$ & Pemetrexed \\
\hline & & $7 \cdot 36 \%$ & Bevacizumab + Pemetrexed & $6 \cdot 84 \%$ & Pemetrexed + Cisplatin \\
\hline & & $6 \cdot 40 \%$ & Docetaxel & $6 \cdot 84 \%$ & Pemetrexed + Unspecified \\
\hline & & $5 \cdot 62 \%$ & Bevacizumab & $5.98 \%$ & Bevacizumab \\
\hline \multirow[t]{6}{*}{ As $2 \mathrm{~L}$ treatment } & Patients who started a $2 \mathrm{~L}$ treatment; $\mathrm{N}$ & 635 & & 96 & \\
\hline & $\%$ patients with at least 1 prescription & $25 \cdot 83 \%$ & Erlotinib & $38.54 \%$ & Erlotinib \\
\hline & & $11 \cdot 34 \%$ & Docetaxel & $7 \cdot 29 \%$ & Pemetrexed \\
\hline & & $8.03 \%$ & Pemetrexed & $7 \cdot 29 \%$ & Gefitinib \\
\hline & & $5 \cdot 83 \%$ & Gemcitabine & $6 \cdot 25 \%$ & Docetaxel + Nintedanib \\
\hline & & $4.09 \%$ & Docetaxel + Nintedanib & $6 \cdot 25 \%$ & Crizotinib \\
\hline \multirow[t]{6}{*}{ As $3 \mathrm{~L}$ treatment } & Patients who started a $3 \mathrm{~L}$ treatment; $\mathrm{N}$ & 242 & & 55 & \\
\hline & $\%$ patients with at least 1 prescription & $20 \cdot 25 \%$ & Erlotinib & $34.55 \%$ & Erlotinib \\
\hline & & $11.98 \%$ & Docetaxel & $12 \cdot 73 \%$ & Docetaxel \\
\hline & & $9 \cdot 92 \%$ & Pemetrexed & $7 \cdot 27 \%$ & Gemcitabine \\
\hline & & $8 \cdot 68 \%$ & Gemcitabine & $7 \cdot 27 \%$ & Vinorelbine \\
\hline & & $5 \cdot 79 \%$ & Nivolumab & $5.45 \%$ & Pemetrexed \\
\hline \multirow[t]{6}{*}{ As $3+\mathrm{L}$ treatment } & Patients who started a $3+\mathrm{L}$ treatment; $\mathrm{N}$ & 90 & & 30 & \\
\hline & $\%$ patients with at least 1 prescription & $12 \cdot 22 \%$ & Nivolumab & $24.00 \%$ & Erlotinib \\
\hline & & $10.00 \%$ & Erlotinib & $16.00 \%$ & Pemetrexed \\
\hline & & $8.89 \%$ & Nintedanib + Docetaxel & $12 \cdot 00 \%$ & Docetaxel \\
\hline & & $6 \cdot 67 \%$ & Pemetrexed & $12 \cdot 00 \%$ & Gemcitabine \\
\hline & & $5 \cdot 56 \%$ & Docetaxel & $8.00 \%$ & Nivolumab \\
\hline
\end{tabular}




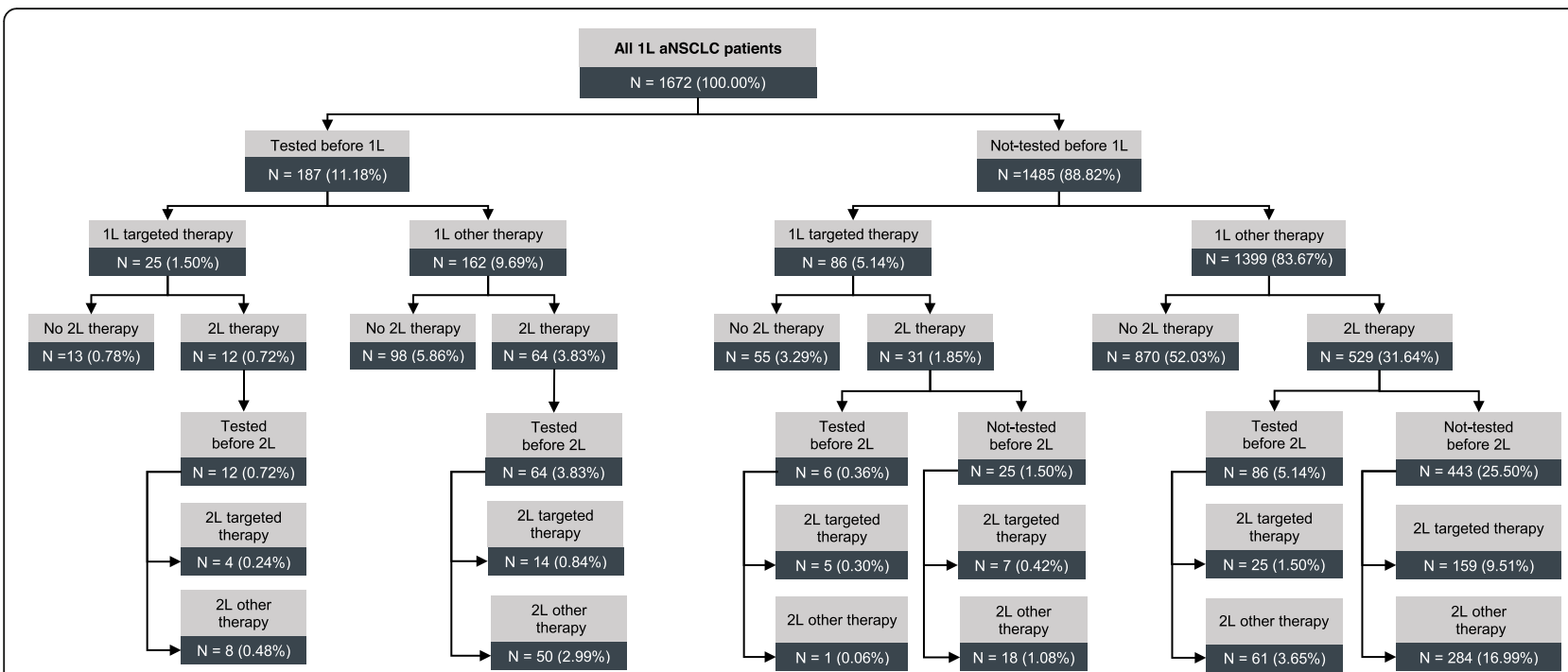

Fig. 2 Mutation testing and observed treatment patterns over time. Describes based on all patients who received at least a $1 \mathrm{~L}$ treatment, distribution of mutation tests and treatment patterns over time. Treatments were divided into targeted treatments and non-targeted treatments including immunotherapy

\section{Overall survival}

Of the 1741 aNSCLC patients, $90 \cdot 5 \% / 73 \cdot 8 \% / 47 \cdot 9 \%$ were alive after $3 / 6 / 12$ months following their incident aNSCLC diagnosis. From 1388 patients who could be observed for 24 months due to data availability, $23.6 \%$ were still alive 2 years following their diagnosis, and from 958 patients who could be observed for 36 months, $14.3 \%$ were still alive 3 years following their diagnosis. From the 122 mutation-positive patients, 97.5\%/91 .8\%/ $74.6 \%$ were alive $3 / 6 / 12$ months following their incident aNSCLC diagnosis. Respective numbers for 24/36 months were $41 \cdot 9 \% / 225 \%$.

Kaplan Meier estimates showed that the median OS after incident diagnosis for all aNSCLC and mutationpositive patients was 351/571 days (Fig. 3). Median OS of patients from date of start of $1 \mathrm{~L} / 2 \mathrm{~L} / 3 \mathrm{~L}$ treatment was 301/194/174 days respectively. Median OS of all aNSCLC patients/mutation positive patients did not change over time, with 319 days for patients with first aNSCLC diagnosis in 2015, and 332/392/356 days for those first diagnosed in 2012/2013/2014.

In a comparison of different treatment patterns across all lines, patients who received at least once an immunotherapy or a TKI combined with a mutation test had the highest OS since incident aNSCLC diagnosis $(p<0.001$ in comparison to chemotherapy group). OS of patients having received a TKI without a mutation test was lower but still significantly higher than in the chemotherapy only group $(p=0 \cdot 006)$. Lowest OS was observed for patients who did not receive any therapy $(p=0.001$ in comparison to chemotherapy only group) (Fig. 3). If respective treatments were compared with regard to OS since start of $1 \mathrm{~L}$ therapy, and only type of $1 \mathrm{~L}$ therapy was taken into account, highest OS was observed for immunotherapy patients $(p=0.002$ in comparison to chemotherapy), followed by mutation-positive patients who received a TKI ( $p=0.011$ in comparison to chemotherapy) (Fig. 4). Survival of patients without a test but receiving a TKI and patients who received a chemotherapy was not statistically different from each other $(p=$ $0.570)$.

In a multivariable Cox regression analysis (Fig. 5) using time to death as dependent variable, higher age $(\mathrm{HR}=1.01, p=0.013)$, a stage IV disease ( $\mathrm{HR}=1.62, p<$ 0.001 ), a higher number of chronic drugs in the preindex period $(\mathrm{HR}=1.03, p<0.001)$ and no therapy $(\mathrm{HR}=$ 1.34, $p=0.031$ ) increased the risk of early death since incident aNSCLC diagnosis. Conversely, female gender $(\mathrm{HR}=0.73, p<0.001)$, an incident diagnosis in 2013 $(\mathrm{HR}=0.77$ in comparison to $2015, p=0.002)$ and treatment with therapies other than conventional chemotherapy (mutation positive \& targeted therapy: $\mathrm{HR}=0.59$, $p<0.001$; immunotherapy only: $\mathrm{HR}=0.36 p<0.001$; no mutation test \& targeted therapy: $\mathrm{HR}=0.85 ; p=0$ 026) were associated with a lower risk of early death. Positive mutation status, number of hospitalizations in the preindex period were not associated with mortality risk and, consequently, excluded from the final regression models.

\section{Discussion}

The main aim of this study was to analyze the realworld treatment of aNSCLC patients and their OS in Germany. The main strength of this analysis is the unselected nature of the dataset which included all aNSCLC 


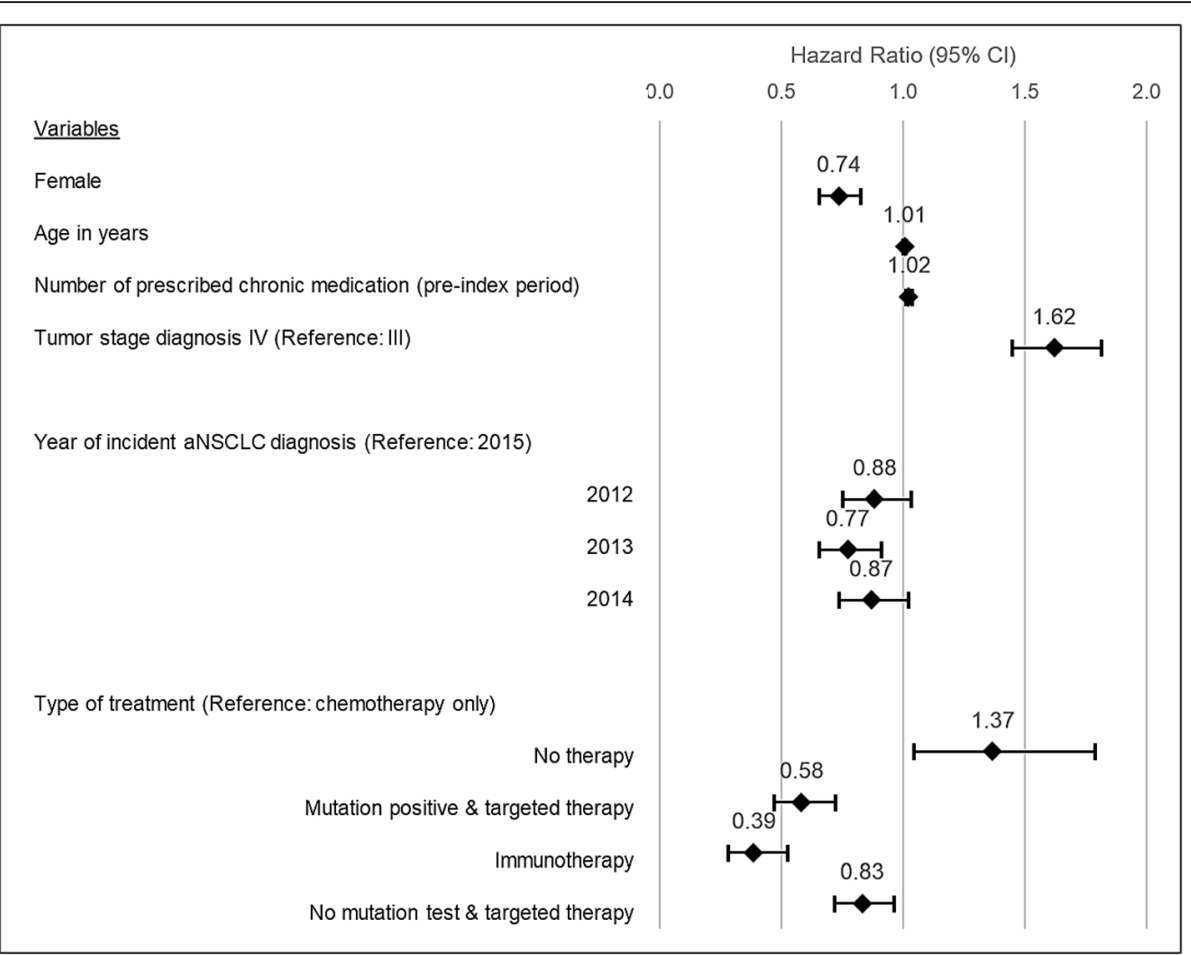

Fig. 5 Multivariate Cox regression analysis of factors associated with early death, since date of incident aNSCLC diagnosis. Shows the results of a multivariable Cox regression analysis exploring predictors of early death. Variables initially included but excluded due to their insignificance were positive mutation status and hospitalizations in pre-index period

patients and all treating physicians irrespective of their type and willingness to participate in a clinical or observational study, with a resulting high external validity of our results. Moreover, our study completely covered both the inpatient and outpatient treatment of patients and, consequently, all sectors of the German healthcare sector. As we included all patients meeting inclusion criteria, our study was also not affected by any selection bias that would lead to an observation of an aboveaverage treated patient sample only, as it can be expected to be the case in most of conducted observational studies/registries. However, we acknowledge that specifically our treatment-related inclusion criteria might have led to an own selection bias that excluded untreated patients as well as patients receiving treatments approved for SCLC and NSCLC from further observation. Moreover, a substantial proportion of patients was already excluded due to non-continuous insurance. We cannot draw conclusions with regard to these excluded patients, as we aimed to observe aNSCLC patients only. As the characteristics of our sample are well in line with previous clinical and observational studies with respect to age, gender distribution and percentage of IIIb/IV patients [27-29], we nevertheless interpret our results to be generalizable with regard to treatment and OS of aNSCLC patients in Germany.
With the exception of aNSCLC stage IIIb patients who receive a potentially curative RT, German diagnosis and treatment guidelines recommend testing for mutations for every diagnosed aNSCLC patient before start of a $1 \mathrm{~L}$ treatment [24]. However, in our sample, only $26.3 \%$ of the observed patients were tested at all, and only $11.2 \%$ received a test between incident aNSCLC diagnosis and start of $1 \mathrm{~L}$ therapy. Only the minority of them were IIIb patients who received a RT. Testing frequency did not increase as the developments and understanding in oncologic mutations progressed over the years, as among patients diagnosed in 2015 only $24.9 \%$ of patients were tested. Our result might have been influenced by the fact that we used proxies for identification of mutation tests, by applying a wide range of outpatient genetic testing codes for identification of mutation tests (Supplementary Table 3). That is why we validated our proxy codes by a subgroup analysis dealing with patients diagnosed with aNSCLC since 01/01/2016 only. From that date onwards, a specific code for mutation tests had been introduced in Germany. In this analysis, only $19.9 \%$ of patients were tested based on the new coding system. So, our above proxies seem to be reliable, and might due to their nature even overestimate the proportion of tested patients.

96.7\% of observed patients were hospitalized since incident aNSCLC diagnosis at least once, $59.6 \%$ of 
observed patients were hospitalized at date of their incident aNSCLC diagnosis. Mutation tests done during inpatient stays might not have been documented properly in our study even if the specific codes are available, as they are not separately reimbursed within the German diagnosis related groups (DRG) system. That would have led to an underestimation of the mutation test rate. However, as German hospitals currently do not get any reimbursement for those tests on top of the DRGs, we do not expect that a substantial percentage of patients was tested during their inpatient stays.

Inclusion of mutation testing into the real-world treatment of aNSCLC patients has been widely discussed in scientific literature [30-35]. For example, a study using US claims data reported that $18 \%$ of newly diagnosed patients with metastatic lung cancer had claims for EGFR testing within 6 months following diagnosis [30]. In qualitative interviews with oncologists treating NSCLC patients in the US, only a minority reported testing every patient regardless of stage, histology, age and smoking status [32]. On the other hand, an example from the Netherlands showed that implementation of guideline recommendations into clinical practice in four hospitals increased the mutation testing rate from 20 $.8 \%$ to $74.4 \%$ within 6 years [36].

Almost 95\% of our sample of German aNSCLC patients received a systemic treatment. This is, compared to previous literature, relatively high. Sacher et al. reported that only $24 \%$ of patients from a large scale data registry in Canada received $1 \mathrm{~L}$ chemotherapy and only $31 \%$ of those patients received $2 \mathrm{~L}$ therapy with more patients receiving treatment over time [37]. David et al. utilizing the National Cancer Data Base (NCDB) in the US reported that $22.3 \%$ of stage IIIB and $25.9 \%$ of stage IV NSCLC patients received no treatment, and 13.9\% and $21.6 \%$ received radiation with no systemic chemotherapy, respectively. Our percentage of patients who received a systemic treatment might overestimate the true quota in this respect, as only lung cancer patients who received a NSCLC treatment (not necessarily since first aNSCLC diagnosis, but since first lung cancer diagnosis) were observed in our study.

Even if almost all of our observed patients received a systemic treatment, the majority of them only received one systemic treatment line within the first year following incident aNSCLC diagnosis (68.8\%; mutationpositive: $37.7 \%$ of all patients). Albeit difficult to observe from claims data records, the most frequent treatment patterns used in $1 \mathrm{~L}$ treatment were pemetrexed and bevacizumab, related combinations $(41.93 \%)$ and docetaxel $(6 \cdot 40 \%)$. This is in line with the treatment guidelines, which recommend $1 \mathrm{~L}$ treatment with pemetrexed or bevacizumab platinum based combinations in patients without mutation and non-squamous NSCLC $[24,38]$.
Pemetrexed combinations as frequent $1 \mathrm{~L}$ treatments were also observed in published literature. Bittoni et al. reported $12 \%$ of patients within the US SEER-Medicare database receiving a pemetrexed and carboplatin combination from 2007 through mid-2013 [39], and Sztankay et al. reported $40.5 \%$ of patients within three Austrian medical centres receiving $1 \mathrm{~L}$ pemetrexed and cisplatin, and $33.3 \%$ receiving $1 \mathrm{~L}$ pemetrexed and carboplatin [40].

In mutation-positive patients, however, a substantial percentage of $>20 \%$ of patients received a pemetrexedbased $1 \mathrm{~L}$ treatment, which is not according to guidelines. This might be related to the fact that more than half of observed mutation tests were done after start of $1 \mathrm{~L}$ therapy. On the other hand, some positively tested patients might still receive non-targeted therapies in clinical practice, which is clearly disadvantageous to patients.

We report a general median survival of 11.5 months in our aNSCLC sample. Mutation-positive patients, based on our proxy definition, had a better median OS of 18.8 months in comparison to the 11.1 months in the not tested/negatively tested patients. Our median OS is well in line with what has been reported in previous observational studies. A US study addressing a community oncology setting reported a median OS of 9.7 months for an aNSCLC patient sample without known EGFR mutations [41]. A European study could identify a median OS of 10.3 months for aNSCLC patients treated with a $1 \mathrm{~L}$ platinum-based chemotherapy [42]. A multinational observational study observed a median OS from first-line therapy initiation of 10.0 (Japan) to 26.7 (Taiwan) months for those tested, and 7.6 (Australia/Brazil) to 19.3 (Taiwan) months for those not tested. Our higher median OS for those patients with a presumed positive testing result is also in line with numbers from previous studies, which reported an OS of up to 39.6 months [14, $36,43-46]$. Additionally, we are very much in line with a previous German observational study which reported a median OS of 18.1-18.4 months for mutation-positive patients who received a TKI during their treatment course [14].

Our multivariable analysis shows that both immunotherapy treatments and TKI treatments are associated with a better OS. However, this result might be strongly influenced by unobserved differences in characteristics of compared patients, and can thus not be generalized to all aNSCLC patients. On the other hand, as many new treatments became available to patients in recent years, we expected an improvement of median OS for the overall aNSCLC population diagnosed in recent years. However, we could not confirm this. OS of patients diagnosed in later years 2014-2015 was not better than that of patients diagnosed in 2012-2013. In association 
with the low testing rates this shows that the real-world treatment of aNSCLC patients' needs to be urgently improved.

\section{Limitations}

We acknowledge some limitations which are mostly related to the nature of the analyzed data. Firstly, we used a retrospective anonymous claims data set which combines the advantages of full data coverage over different sectors of healthcare (inpatient and outpatient treatment) and absence of any study site/patient selection bias due to the study itself with the disadvantage of lack of clinical details as mainly data used for reimbursement purposes are available in such a dataset. Nevertheless, claims data are a often used data source for observational research, and have frequently been used in the area of lung cancer as well $[30,39]$. In addition to that, usage of a regional claims database as the used AOK PLUS database might imply a bias by itself. However, due to the German legal framework, health service reimbursement rules are identical across Germany, so that no bias could result from using a database from one database. There remains the risk of a regional bias, as AOK PLUS insures persons in two German states only. We cannot rule out this bias risk completely, but previous studies in non-cancer diseases done with AOK PLUS data as well that there are no major regional differences in health care structures and services between Saxon/Thuringia and other German states [47].

Secondly, as already noted above, our method to identify mutation tests might have led to both an under- and overestimation of testing rates. Thirdly, our method of identifying the index dates of the patients in the included sample might have led to the overestimation of OS. The index date was identified as the first inpatient or outpatient incident aNSCLC diagnosis. Whereas the exact dates of inpatient data were available, for outpatient diagnoses only the respective quarter of the year was available. Here, we used the first day in a quarter as index date. In our dataset, $56.3 \%$ of all aNSCLC patients (981 out of 1741 patients) were included based on an inpatient diagnosis as index date. For the remaining 760 patients (43.7\%), above mentioned overestimation of up to three months might have occurred.

Fourthly, mutation-positive patients were identified based on whether they received a targeted treatment any time following an observed mutation test. In case a patient received a mutation test with a negative result, but still received a targeted treatment at any time after that test, we wrongly assumed that this patient was tested positively. Moreover, it should be noted that according to German treatment guidelines, Erlotinib can also be prescribed as $2 \mathrm{~L}+$ treatment in mutation negative NSCLC patients in case other therapy options are not suitable, which might have led to an overestimation of the percentage of mutation positive patients in the analysis. Furthermore, taking into account targeted treatment as an inclusion criterion for the sample of mutation positive aNSCLC patients, reporting of the most often prescribed agents in $1 \mathrm{~L}, 2 \mathrm{~L}$ or $3 \mathrm{~L}$ may have been biased, even if all observed treatments within the selected patient group have been reported.

Fifth, as aNSCLC patients are likely to be hospitalized, inpatient chemotherapy treatment had to be considered throughout the analysis. However, for older chemotherapy agents not reimbursed separately by German payors but as part of DRGs, a chemotherapy was identifiable via a specific operational procedure code, but not the type of agent. Thus, we assumed that any unspecified chemotherapy treatment during a hospitalization was the same as the one prior to the inpatient stay, which could have led to an underestimation of lines of therapy patients received if many inpatient hospitalizations were associated with a change of chemotherapy.

Sixth, treatments administered within clinical studies might not have been recorded in our claims dataset as study medication is paid by the sponsors of these studies. Moreover, the duration of treatment lines was likely to be overestimated as the end and not the beginning of a time gap (45 days) in treatment prescriptions was assumed to be the end of the treatment line. Finally, identification of treatment lines in this analysis did not take into account maintenance therapies, which might have led to a higher than actual number of treatment lines being reported.

\section{Conclusions}

Median OS of German aNSCLC patients in the real world is low, but in line with other countries. Patients with a positive EGFR/ALK/ROS-1 mutation test in association with a targeted treatment do have a better OS than those not receiving a targeted treatment and/or those who did not receive a mutation test.

Despite the introduction of new treatments in aNSCLC, the real-world survival prognosis for patients in advanced stages of NSCLC did not change in recent years. Mutation testing for aNSCLC patients is still not a common practice, despite clear guideline recommendations and availability of targeted treatments. Therefore, there is an urgent need to improve the real-world treatment of these patients.

\section{Supplementary information}

Supplementary information accompanies this paper at https://doi.org/1 0.1186/s12885-020-06738-z

Additional file 1: Table S1. Treatments approved for NSCLC and/or SCLC 
Additional file 2: Table S2. Advanced tumor stage classification descriptions and respective ICD-10 codes

Additional file 3: Table S3. Mutation test codes Additional file 4: Table S4. Logistic regression model for mutation testing

Additional file 5: Table S5. Logistic regression model for type of $1 \mathrm{~L}$ treatment

\section{Abbreviations}

ALK: Anaplastic lymphoma kinase; aNSCLC: Advanced non-small cell lung cancer; ATC: Anatomical therapeutic chemical classification; CCl: Charlson Comorbidity Index; DRG: Diagnosis related groups; EGFR: Epidermal growth factor receptor; NCDB: National Cancer Data Base; NSCLC: Non-small cell lung cancer (NSCLC); OPS: Operational and procedure codes; OR: Odds Ratio; OS: Overall survival; ROS-1: Proto-oncogene receptor tyrosine kinase; RT: Radiotherapy; SmPCs: Summary of Product Characteristics; TKl: Tyrosine kinase inhibitor; UICC: Union for International Cancer Control's

\section{Acknowledgements}

Not applicable.

\section{Authors' contributions}

All authors (FH, DM, TL, DC, UM, TW, FG) were involved in the conceptualization and the design of the study and interpretation of the data. $\mathrm{FH}, \mathrm{TW}$, and SM analyzed the data and drafted the manuscript. All authors (FH, DM, TL, DC, UM, TW, FG) critically reviewed the article and made substantial contributions to the finalization of the manuscript, especially including the discussion section, and have given their final approval of the version to be submitted.

\section{Funding}

This study was supported by Janssen Pharmaceutical Companies of Johnson $\&$ Johnson. The funder of the study was responsible for the study design and funded the collection and analysis of the data. All authors, including those employed by Janssen Pharmaceutical Companies of Johnson \& Johnson, participated in the data interpretation and writing of the manuscript.

\section{Availability of data and materials}

The data used in this study are abstracted from individual patient records and are not publicly available.

\section{Ethics approval and consent to participate}

Because of the non-interventional, retrospective nature of analyzed data and because our analysis involved an anonymized dataset, neither ethical review nor informed consent of the patients was required. However, the study protocol was reviewed and approved by a scientific steering committee to which all the authors belonged. Moreover, the study protocol was reviewed and approved by the sickness fund (AOK PLUS), before access to the data was permitted.

\section{Consent for publication}

Not applicable.

\section{Competing interests}

Fränce Hardtstock, Thomas Wilke and Diana Cizova participated in this study as staff members of IPAM; the work of IPAM in this study was financed by Janssen Pharmaceutical Companies of Johnson \& Johnson. Thomas Wilke reports honoraria from several pharmaceutical/consultancy companies (Novo Nordisk, Abbvie, Merck, GSK, BMS, LEO Pharma, Astra Zeneca, Bayer, Boehringer Ingelheim, Pharmerit). David Myers and Tracy Li are employees of Janssen Pharmaceutical Companies of Johnson \& Johnson. Ulf Maywald is an employee of AOK PLUS and reports Honoria from Roche and MSD. Frank Griesinger participated as a clinical advisor in the Scientific Steering Board. The authors report no other conflicts of interest in this work.

\section{Author details}

${ }^{1}$ IPAM e.V, Alter Holzhafen 19, 23966 Wismar, Germany. ${ }^{2}$ The Janssen Pharmaceutical Companies of Johnson \& Johnson, Janssen-Cilag AB,
Stockholm, Sweden. ${ }^{3}$ The Janssen Pharmaceutical Companies of Johnson \& Johnson, Janssen Global Services, Raritan, NJ, USA. ${ }^{4}$ AOK PLUS, Sternplatz 7 01067 Dresden, Germany. ${ }^{5}$ Universitätsklinik für Innere Medizin-Onkologie, Cancer Center Oldenburg, Pius-Hospital Universitätsmedizin Oldenburg, Georgstrasse 12, 26121 Oldenburg, Germany.

Received: 28 August 2019 Accepted: 12 March 2020

Published online: 30 March 2020

\section{References}

1. The Global Cancer Observatory. World fact sheet: Cancer. http://gco.iarc.fr/ today/data/factsheets/populations/900-world-fact-sheets.pdf. Accessed 10 Jan 102018.

2. The Global Cancer Observatory. Lung Cancer fact sheet. http://gco.iarc.fr/ today/data/factsheets/cancers/15-Lung-fact-sheet.pdf. Accessed 10 Jan 2018

3. Martín-Sánchez JC, Lunet N, González-Marrón A, et al. Projections in breast and lung Cancer mortality among women: a Bayesian analysis of 52 countries worldwide. Cancer Res. 2018;78(15):4436-42. https://doi.org/10. 1158/0008-5472.CAN-18-0187

4. Jemal A, Bray F, Center MM, Ferlay J, Ward E, Forman D. Global cancer statistics. CA Cancer J Clin. 2011;61(2):69-90. https://doi.org/10.3322/caac. 20107

5. Goldstraw P, Chansky K, Crowley J, et al. The IASLC lung Cancer staging project: proposals for revision of the TNM stage groupings in the forthcoming (eighth) edition of the TNM classification for lung Cancer. J Thorac Oncol. 2016;11(1):39-51. https://doi.org/10.1016/j.jtho.2015.09.009 .

6. Ettinger DS, Akerley W, Bepler G, et al. Non-small cell lung cancer. J Natl Compr Cancer Netw. 2010;8(7):740-801.

7. Gaughan EM, Costa DB. Genotype-driven therapies for non-small cell lung cancer: focus on EGFR, KRAS and ALK gene abnormalities. Ther Adv Med Oncol. 2011;3(3):113-25. https://doi.org/10.1177/1758834010397569

8. Rosell R, Carcereny E, Gervais R, et al. Erlotinib versus standard chemotherapy as first-line treatment for European patients with advanced EGFR mutation-positive non-small-cell lung cancer (EURTAC): a multicentre, open-label, randomised phase 3 trial. Lancet Oncol. 2012;13(3):239-46. https://doi.org/10.1016/S1470-2045(11)70393-X.

9. Warth A, Muley T, Dienemann H, et al. ROS1 expression and translocations in non-small-cell lung cancer: Clinicopathological analysis of 1478 cases. Histopathology. 2014;65(2):187-94. https://doi.org/10.1111/his.12379.

10. Bergethon $\mathrm{K}$, Shaw AT, Ou S-HI, et al. ROS1 rearrangements define a unique molecular class of lung cancers. J Clin Oncol. 2012;30(8):863-70. https://doi. org/10.1200/JCO.2011.35.6345

11. Shaw AT, Ou S-HI, Bang Y-J, et al. Crizotinib in ROS1-rearranged non-smallcell lung cancer. N Engl J Med. 2014;371(21):1963-71. https://doi.org/10. 1056/NEJMoa1406766

12. Ma BBY, Rudin CM, Cervantes A, et al. 4410 Preliminary safety and clinical activity of erlotinib plus atezolizumab from a Phase lb study in advanced NSCLC. Ann Oncol. 2016;27(suppl_9). https://doi.org/10.1093/annonc/ mdw594.005

13. The Clinical Lung Cancer Genome Project (CLCGP) and Network Genomic Medicine. A genomics-based classification of human lung tumors. Sci Trans Med. 2013;5(209):209ra153. https://doi.org/10.1126/scitranslmed.3006802

14. Schuette W, Schirmacher P, Eberhardt WEE, et al. Treatment decisions, clinical outcomes, and pharmacoeconomics in the treatment of patients with EGFR mutated stage III/IV NSCLC in Germany: an observational study. BMC Cancer. 2018;18(1):135. https://doi.org/10.1186/s12885-018-4032-3

15. Brahmer J, Reckamp KL, Baas P, et al. Nivolumab versus Docetaxel in advanced squamous-cell non-small-cell lung Cancer. N Engl J Med. 2015; 373(2):123-35. https://doi.org/10.1056/NEJMoa1504627

16. Borghaei $H$, Paz-Ares L, Horn L, et al. Nivolumab versus Docetaxel in advanced nonsquamous non-small-cell lung Cancer. N Engl J Med. 2015; 373(17):1627-39. https://doi.org/10.1056/NEJMoa1507643.

17. Herbst RS, Baas P, Kim D-W, et al. Pembrolizumab versus docetaxel for previously treated, PD-L1-positive, advanced non-small-cell lung cancer (KEYNOTE-010): a randomised controlled trial. Lancet. 2016:387(10027):1540_ 50. https://doi.org/10.1016/S0140-6736(15)01281-7

18. AWMF. S3-Leitlinie Prävention, Diagnostik, Therapie und Nachsorge des Lungenkarzinoms: Langversion 1.0 - Februar 2018 AWMF-Registernummer: 020/007OL. https://www.awmf.org/uploads/tx_szleitlinien/020-007OL_I_S3_ Lungenkarzinom_2018-03.pdf. Accessed 11 Dec 2018. 
19. Farhat FS, Houhou W. Targeted therapies in non-small cell lung carcinoma: what have we achieved so far? Ther Adv Med Oncol. 2013;5(4):249-70. https://doi.org/10.1177/1758834013492001.

20. Testa U, Castelli G, Pelosi E. Lung Cancers: Molecular Characterization, Clonal Heterogeneity and Evolution, and Cancer Stem Cells. Cancers (Basel). 2018; 10(8). https://doi.org/10.3390/cancers10080248 .

21. Lemjabbar-Alaoui $H$, Hassan OU, Yang Y-W, Buchanan P. Lung cancer: biology and treatment options. Biochim Biophys Acta. 2015;1856(2):189210. https://doi.org/10.1016/j.bbcan.2015.08.002

22. Griesinger F, Eberhardt W, Früh $M$, et al. Lungenkarzinom, nicht-kleinzellig (NSCLC): Onkopedia Leitlinie. 2018. https://www.onkopedia.com/de/ onkopedia/guidelines/lungenkarzinom-nicht-kleinzellig-nsclc/@@view/html/ index.html.

23. Planchard D, Popat S, Kerr K, et al. Metastatic non-small cell lung cancer: ESMO Clinical Practice Guidelines for diagnosis, treatment and follow-up. Ann Oncol. 2018;29(Supplement_4):iv192-237. https://doi.org/10.1093/ annonc/mdy 275

24. DGHO. Deutsche Gesellschaft für Hämatologie und Medizinische Onkologie e.V. Leitlinie: Lungenkarzinom, nicht-kleinzellig (NSCLC): Empfehlungen der Fachgesellschaft zur Diagnostik und Therapie hämatologischer und onkologischer Erkrankungen. Berlin; 2017. https://www.onkopedia.com/de/ onkopedia/guidelines/lungenkarzinom-nicht-kleinzellig-nsclc/@@view/html/ index.html. Accessed 10 Oct 2017.

25. EMA. Summary Of Product Characteristics. https://www.ema.europa.eu/. Accessed 14 Oct 2017.

26. Kassenärztliche Bundesvereinigung. Einheitlicher Bewertungsmaßstab: EBM. http://www.kbv.de/html/online-ebm.php. Accessed 30 Oct 2018.

27. Davies J, Patel M, Gridelli C, de Marinis F, Waterkamp D, McCusker ME. Realworld treatment patterns for patients receiving second-line and third-line treatment for advanced non-small cell lung cancer: a systematic review of recently published studies. PLoS One. 2017;12(4):e0175679. https://doi.org/ 10.1371/journal.pone.0175679

28. Owonikoko TK, Ragin C, Chen Z, et al. Real-world effectiveness of systemic agents approved for advanced non-small cell lung cancer: a SEER-Medicare analysis. Oncologist. 2013;18(5):600-10. https://doi.org/10.1634/ theoncologist.2012-0480

29. Arunachalam A, Li H, Bittoni MA, et al. Real-world treatment patterns, overall survival, and occurrence and costs of adverse events associated with second-line therapies for Medicare patients with advanced non-small-cell lung Cancer. Clin Lung Cancer. 2018;19(5):e783-99. https://doi.org/10.1016/j. cllc.2018.05.016

30. Shen C, Kehl KL, Zhao B, Simon GR, Zhou S, Giordano SH. Utilization patterns and trends in epidermal growth factor receptor (EGFR) mutation testing among patients with newly diagnosed metastatic lung Cancer. Clin Lung Cancer. 2017;18(4):e233-41. https://doi.org/10.1016/j.cllc.2016.11.002 .

31. Chawla A, Peeples M, Li N, Anhorn R, Ryan J, Signorovitch J. Real-world utilization of molecular diagnostic testing and matched drug therapies in the treatment of metastatic cancers. J Med Econ. 2018;21(6):543-52. https:// doi.org/10.1080/13696998.2017.1423488

32. Arney J, Helm A, Crook T, Braun UK, Chen GJ, Hayes TG. Utilization of genomic testing in advanced non-small cell lung cancer among oncologists in the veterans health administration. Lung Cancer. 2018;116:25-9. https:// doi.org/10.1016/j.lungcan.2017.12.006

33. Kerr KM, Bubendorf L, Edelman MJ, et al. Second ESMO consensus conference on lung cancer: pathology and molecular biomarkers for nonsmall-cell lung cancer. Ann Oncol. 2014;25(9):1681-90. https://doi.org/10. 1093/annonc/mdu145

34. Pirker R, Herth FJF, Kerr KM, et al. Consensus for EGFR mutation testing in non-small cell lung cancer: results from a European workshop. J Thorac Oncol. 2010;5(10):1706-13. https://doi.org/10.1097/JTO.0b013e3181f1c8de

35. Lindeman NI, Cagle PT, Beasley MB, et al. Molecular testing guideline for selection of lung cancer patients for EGFR and ALK tyrosine kinase inhibitors: guideline from the College of American Pathologists, International Association for the Study of Lung Cancer, and Association for Molecular Pathology. J Thorac Oncol. 2013;8(7):823-59. https://doi.org/10. 1097/JTO.0b013e318290868f

36. Sluga R, VAN DEN, Borne BEEM, Roepman P, BJM P, Kastelijn EA, Schramel FMNH. Utilization of Molecular Testing and Survival Outcomes of Treatment with First- or Second-line Tyrosine Kinase Inhibitors in Advanced Non-small Cell Lung Cancer in a Dutch Population. Anticancer Res. 2018;38(1):393-400. https://doi.org/10.21873/anticanres.12235.
37. Sacher AG, Le LW, Lau A, Earle CC, Leighl NB. Real-world chemotherapy treatment patterns in metastatic non-small cell lung cancer: are patients undertreated? Cancer. 2015;121(15):2562-9. https://doi.org/10.1002/cncr. 29386

38. Scarpace SL. Metastatic squamous cell non-small-cell lung cancer (NSCLC): disrupting the drug treatment paradigm with immunotherapies. Drugs Context. 2015;4:212289. https://doi.org/10.7573/dic.212289.

39. Bittoni MA, Arunachalam A, Li H, et al. Real-world treatment patterns, overall survival, and occurrence and costs of adverse events associated with firstline therapies for Medicare patients 65 years and older with advanced nonsmall-cell lung Cancer: a retrospective study. Clin Lung Cancer. 2018. https://doi.org/10.1016/j.cllc.2018.04.017

40. Sztankay M, Giesinger JM, Zabernigg A, et al. Clinical decision-making and health-related quality of life during first-line and maintenance therapy in patients with advanced non-small cell lung cancer (NSCLC): findings from a real-world setting. BMC Cancer. 2017;17(1):565. https://doi.org/10.1186/ s12885-017-3543-7.

41. Abernethy AP, Arunachalam A, Burke T, et al. Real-world first-line treatment and overall survival in non-small cell lung cancer without known EGFR mutations or ALK rearrangements in US community oncology setting. PLoS One. 2017;12(6):e0178420. https://doi.org/10.1371/journal.pone.0178420

42. Moro-Sibilot D, Smit E, de Castro Carpeño J, et al. Outcomes and resource use of non-small cell lung cancer (NSCLC) patients treated with first-line platinum-based chemotherapy across Europe: FRAME prospective observational study. Lung Cancer. 2015;88(2):215-22. https://doi.org/10. 1016/j.lungcan.2015.02.011

43. Faehling M, Schwenk B, Kramberg S, et al. Oncogenic driver mutations, treatment, and EGFR-TKI resistance in a Caucasian population with nonsmall cell lung cancer: survival in clinical practice. Oncotarget. 2017;8(44): 77897-914. https://doi.org/10.18632/oncotarget.20857.

44. Cheng Y, Wang Y, Zhao J, et al. Real-world EGFR testing in patients with stage IIIB/IV non-small-cell lung cancer in North China: a multicenter, noninterventional study. Thorac Cancer. 2018. https://doi.org/10.1111/17597714.12859

45. Gobbini E, Galetta D, Tiseo M, et al. Molecular profiling in Italian patients with advanced non-small-cell lung cancer: an observational prospective study. Lung Cancer. 2017;111:30-7. https://doi.org/10.1016/j.lungcan.2017.06 009 .

46. Lee DH, Tsao M-S, Kambartel K-O, et al. Molecular testing and treatment patterns for patients with advanced non-small cell lung cancer: PIvOTAL observational study. PLoS One. 2018;13(8):e0202865. https://doi.org/10.1371/ journal.pone.0202865

47. Wilke T, Picker N, Mueller S, et al. Real-world insulin therapy in German type 2 diabetes mellitus patients: patient characteristics, treatment patterns, and insulin dosage. Diabetes Metab Syndr Obes. 2019;12:1225-37. https://doi. org/10.2147/DMSO.S214288

\section{Publisher's Note}

Springer Nature remains neutral with regard to jurisdictional claims in published maps and institutional affiliations.

Ready to submit your research? Choose BMC and benefit from:

- fast, convenient online submission

- thorough peer review by experienced researchers in your field

- rapid publication on acceptance

- support for research data, including large and complex data types

- gold Open Access which fosters wider collaboration and increased citations

- maximum visibility for your research: over $100 \mathrm{M}$ website views per year

At $\mathrm{BMC}$, research is always in progress.

Learn more biomedcentral.com/submission 